\title{
Natural vegetation restoration of Liaodong oak (Quercus liaotungensis Koidz.) forests rapidly increased the content and ratio of inert carbon in soil macroaggregates
}

\author{
SUN Lipeng ${ }^{1}$, HE Lirong ${ }^{2}$, WANG Guoliang ${ }^{1}$, JING Hang $^{1}$, LIU Guobin ${ }^{1 *}$ \\ ${ }^{1}$ Institute of Soil and Water Conservation, Northwest A\&F University, Yangling 712100, China; \\ ${ }^{2}$ Shaanxi Provincial Land Engineering Construction Group Co., Ltd., Xi'an 710075, China
}

\begin{abstract}
The lack of clarity of how natural vegetation restoration influences soil organic carbon (SOC) content and SOC components in soil aggregate fractions limits the understanding of SOC sequestration and turnover in forest ecosystems. The aim of this study was to explore how natural vegetation restoration affects the SOC content and ratio of SOC components in soil macroaggregates $(>250 \mu \mathrm{m})$, microaggregates $(53-250 \mu \mathrm{m})$, and silt and clay $(<53 \mu \mathrm{m})$ fractions in 30-, 60-, 90- and 120-year-old Liaodong oak (Quercus liaotungensis Koidz.) forests, Shaanxi, China in 2015. And the associated effects of biomasses of leaf litter and different sizes of roots $(0-0.5,0.5-1.0,1.0-2.0$ and $>2.0 \mathrm{~mm}$ diameter) on SOC components were studied too. Results showed that the contents of high activated carbon (HAC), activated carbon (AC) and inert carbon (IC) in the macroaggregates, microaggregates and silt and clay fractions increased with restoration ages. Moreover, IC content in the microaggregates in topsoil $(0-20 \mathrm{~cm})$ rapidly increased; peaking in the 90-year-old restored forest, and was 5.74 times higher than AC content. In deep soil (20-80 $\mathrm{cm}$ ), IC content was 3.58 times that of AC content. Biomasses of $0.5-1.0 \mathrm{~mm}$ diameter roots and leaf litter affected the content of aggregate fractions in topsoil, while the biomass of $>2.0 \mathrm{~mm}$ diameter roots affected the content of aggregate fractions in deep soil. Across the soil profiles, macroaggregates had the highest capacity for HAC sequestration. The effects of restoration ages on soil aggregate fractions and SOC content were less in deep soil than in topsoil. In conclusion, natural vegetation restoration of Liaodong oak forests improved the contents of SOC, especially IC within topsoil and deep soil. The influence of IC on aggregate stability was greater than the other SOC components, and the aggregate stability was significantly affected by the biomasses of litter, $0.5-1.0 \mathrm{~mm}$ diameter roots in topsoil and $>2.0 \mathrm{~mm}$ diameter roots in deep soil. Natural vegetation restoration of Liaodong oak forests promoted SOC sequestration by soil macroaggregates.
\end{abstract}

Keywords: activated carbon; leaf litter; soil organic carbon; soil aggregates; silt and clay; Shaanxi

Citation: SUN Lipeng, HE Lirong, WANG Guoliang, JING Hang, LIU Guobin. 2019. Natural vegetation restoration of Liaodong oak (Quercus liaotungensis Koidz.) forests rapidly increased the content and ratio of inert carbon in soil macroaggregates. Journal of Arid Land, 11(6): 928-938. https://doi.org/10.1007/s40333-019-0004-y

\section{Introduction}

Rising atmospheric concentration of $\mathrm{CO}_{2}$ that has contributed to global warming is a critical

*Corresponding author: LIU Guobin (E-mail: gbliu@ms.iswc.ac.cn)

Received 2018-02-23; revised 2018-12-11; accepted 2019-01-13

(C) Xinjiang Institute of Ecology and Geography, Chinese Academy of Sciences, Science Press and Springer-Verlag GmbH Germany, part of Springer Nature 2019 
environmental issue. Natural vegetation restoration is a management approach that increases carbon sequestration rates in soil by increasing vegetation cover, and is perceived as the most effective technique to decrease atmospheric concentrations of $\mathrm{CO}_{2}$ (He et al., 2017). Natural vegetation restoration changes soil organic carbon (SOC) content in soil aggregate fractions. For example, natural vegetation restoration increased the content of SOC in the macroaggregates (Barthes et al., 2008). Moreover, the effects of natural vegetation restoration were variable (Liao et al., 2016; Bi et al., 2018), and were probably associated with variation in environmental factors, such as soil type, vegetation type and temperature (Zhou et al., 2012). Recent research has shown that the turnover rate of active organic carbon (AOC) varied with the sizes of soil aggregate fractions (Tobiasova et al., 2016; Yao et al., 2017). Furthermore, contents of SOC and AOC decreased with vegetation succession, while the content of organic matter $(\mathrm{OM})$ increased ( $\mathrm{Li}$ et al., 2014). Meanwhile, the coarse intra-aggregate particulate organic matter-carbon (iPOM-C) tended to increase with vegetation succession, while fine iPOM-C concentrations tended to fluctuate (Cheng et al., 2015). The physical and chemical protection of organic carbon by soil aggregate fractions may lead to the accumulation of inert carbon (IC). For example, Wang et al. (2016) found that afforestation decreased the coarse particle organic carbon fraction, but increased the recalcitrant mineral-associated SOC content. Natural vegetation restoration is known to increase SOC content in surface soil (0-20 cm) (Wei et al., 2013), and forest restoration has been shown to increase SOC content in deep soil due to root turnover and/or transfer of SOC from surface soil to deep soil through soil pore space of rainfall percolation (Zelenev et al., 2000). However, accumulation and decomposition processes among the SOC fractions in deep soil aggregate fractions may be different from those in surface soil (Callesen et al., 2016) due to the variations in temperature, soil moisture and microbial activities. The influence of vegetation on the accumulation processes of SOC components in deep soil remains unknown.

SOC in soil aggregate fractions primarily originates from leaf and root litter, and root secretions. The effects of leaf and root litter on the contents of SOC in soil aggregate fractions may be different and vary with soil layer (Lin et al., 2017). Soil aggregate fractions and SOC contents in surface soil have been shown to be mainly affected by leaf litter and fine roots (Sanaullah et al., 2011). It is likely that the influences of leaf and root litter on SOC content vary with soil layers, because differences in chemical composition, anatomical structure and turnover rates have been recorded among different sizes of fine roots (Wang et al., 2007).

The aim of this study was to explore how natural vegetation restoration affects the content and ratio of SOC components in soil aggregate fractions. And we hypothesize that (1) natural vegetation restoration of Liaodong oak (Quercus liaotungensis Koidz.) forests increases SOC content regardless of aggregate size, but the accumulation rates are more rapid in the macroaggregates of surface soil than in the microaggregates of deep soil; and (2) SOC content is mainly affected by the biomass of leaf little and roots in surface soil aggregate fractions and the biomass of fine roots in deep soil aggregate fractions.

\section{Materials and methods}

\subsection{Study area and sampling}

The study area is located in the Renjiatai Forest Farm, Shaanxi, China $\left(36^{\circ} 05^{\prime} \mathrm{N}, 109^{\circ} 11^{\prime} \mathrm{E}\right.$; 920-1680 m a.s.1), in a girder loess hilly-gully region with a mean gully density of $4.5 \mathrm{~km} / \mathrm{km}^{2}$. The annual average temperature is $9.0^{\circ} \mathrm{C}$, and the average annual precipitation is $576.7 \mathrm{~mm}$, of which about $60 \%-70 \%$ falls from July to September. Surface soils are principally brown forest soils and forest canopy density is $70 \%$ and coverage exceeds $90 \%$. Natural vegetation in the study area is represented by Liaodong oak, pine and birch forests, among which Liaodong oak forest becomes the local climax community, and is dominated by $Q$. liaotungensis, Populus davidiana and Betula platyphyllum, with understorey comprising Spiraea salicifolia, Sophora viciifoli and Ostryopsis davidiana shrub species, Carex lanceolata and Artemisia gmelinii herbaceous flora (Zhu et al., 2008).

The study was conducted from 15 to 28 September, 2015 in 30-, 60-, 90- and 120-year-old 
Liaodong oak forests. Grassland converted from farmland was considered as the control. Five plots in each of the five stand types with an area above $1 \mathrm{hm} \times 1 \mathrm{hm}$ were positioned on a southeastern slope with the gradients of $15^{\circ}-30^{\circ}$ (Table 1), and soil samples were taken from four $20 \mathrm{~m} \times 20 \mathrm{~m}$ quadrats in each plot.

Table 1 Characteristics of the restored forests

\begin{tabular}{|c|c|c|c|c|c|}
\hline Stand type & Age (a) & Elevation (m) & Slope gradient $\left(^{\circ}\right)$ & Slope direction $\left(^{\circ}\right)$ & Dominant species \\
\hline Converted grassland & CK & $1077 \pm 21$ & $15 \pm 2$ & $132 \pm 5$ & Carex lanceolata \\
\hline Young forest & 30 & $1157 \pm 16$ & $25 \pm 1$ & $109 \pm 11$ & $\begin{array}{l}\text { Quercus liaotungensis, } \\
\text { Pyrus betulaefolia }\end{array}$ \\
\hline Semi-mature forest & 60 & $1138 \pm 13$ & $26 \pm 2$ & $155 \pm 8$ & $\begin{array}{l}\text { Quercus liaotungensis, } \\
\text { Pyrus betulaefolia, } \\
\text { Acer spp. }\end{array}$ \\
\hline Mature forest & 90 & $1321 \pm 24$ & $25 \pm 3$ & $170 \pm 12$ & $\begin{array}{l}\text { Quercus liaotungensis, } \\
\text { Pyrus betulaefolia, } \\
\text { Acer spp. }\end{array}$ \\
\hline Veteran forest & 120 & $1396 \pm 11$ & $28 \pm 1$ & $168 \pm 6$ & $\begin{array}{l}\text { Quercus liaotungensis, } \\
\text { Populus tremula }\end{array}$ \\
\hline
\end{tabular}

Note: CK, control; Slope direction ranges from north $\left(0^{\circ}\right)$ to east $\left(90^{\circ}\right)$. Mean \pm SD.

Within each plot, undisturbed soil cores at $100 \mathrm{~cm}$ depth were sampled within an area of 1.0 $\mathrm{m} \times 0.5 \mathrm{~m}$, and soil moisture and bulk density were measured. Roots manually collected at $20-\mathrm{cm}$ intervals along the $100-\mathrm{cm}$ profile were separated according to their diameters into finest $(<0.5$ $\mathrm{mm})$, finer $(0.5-1.0 \mathrm{~mm})$, fine $(1.0-2.0 \mathrm{~mm})$ and thick $(>2.0 \mathrm{~mm})$ roots that were cleaned and dried at $70^{\circ} \mathrm{C}$ to a constant weight to determine biomass (Wu et al., 2017). Leaf litter was collected from three quadrats with an area of $10 \mathrm{~cm} \times 10 \mathrm{~cm}$, and then dried to a constant weight at $70^{\circ} \mathrm{C}$ to determine biomass.

\subsection{Determination of soil fertility parameters}

We divided soil samples into the macroaggregates $(>250 \mu \mathrm{m})$, microaggregates $(53-250 \mu \mathrm{m})$, and silt and clay $(<53 \mu \mathrm{m})$ fractions based on the wet screening method that uses automatic shock sieves (250 and $53 \mu \mathrm{m})$ (Cambardella et al., 1993).

SOC can be classified as high activated carbon (HAC), activated carbon (AC) and IC. SOC content was determined using the external heating potassium dichromate method. HAC and AC contents were determined using the potassium permanganate $\left(\mathrm{KMnO}_{4}\right)$ oxidation method. IC content was calculated as the difference between total organic carbon and AC (Huo et al., 2012).

\subsection{Statistical analyses}

Mean weight diameter (MWD; mm) was calculated as follows (Elliott, 1986):

$$
\mathrm{MWD}=\sum_{i=1}^{n} x_{i} w_{i},
$$

where $x_{i}$ is the mean diameter of each class of aggregates $(\mathrm{mm}) ; w_{i}$ is the proportion of each class of aggregates (\%); and $n$ is the number of aggregates.

HAC and AC are obtained from experimental data. IC is the difference between SOC and HAC. Relationship between SOC components and biomasses of different sizes of roots and leaf litter in aggregate fractions was tested by variance analysis. Multiple comparisons were tested using Tukey HSD of R software (v3.3.2) at $P<0.05$ level.

\section{Results}

\subsection{MWD and soil aggregate fractions}

We found that the MWD and percentage of macroaggregates increased with restoration ages, and the greatest values of them were found in topsoil of the 90 -year-old forest $(21.09 \%$ and $23.85 \%$ higher than those of control, respectively), and in deep soil of the 60 -year-old forest $(16.33 \%$ and $19.19 \%$ higher than those of control, respectively) (Fig. 1). However, the lowest values of MWD and macroaggregates were occurred in topsoil of the 90 -year-old forest $(51.36 \%$ and $53.55 \%$ 
lower than those of control, respectively) and in deep soil of the 60 -year-old forest $(35.76 \%$ and $19.97 \%$ lower than those of control, respectively).
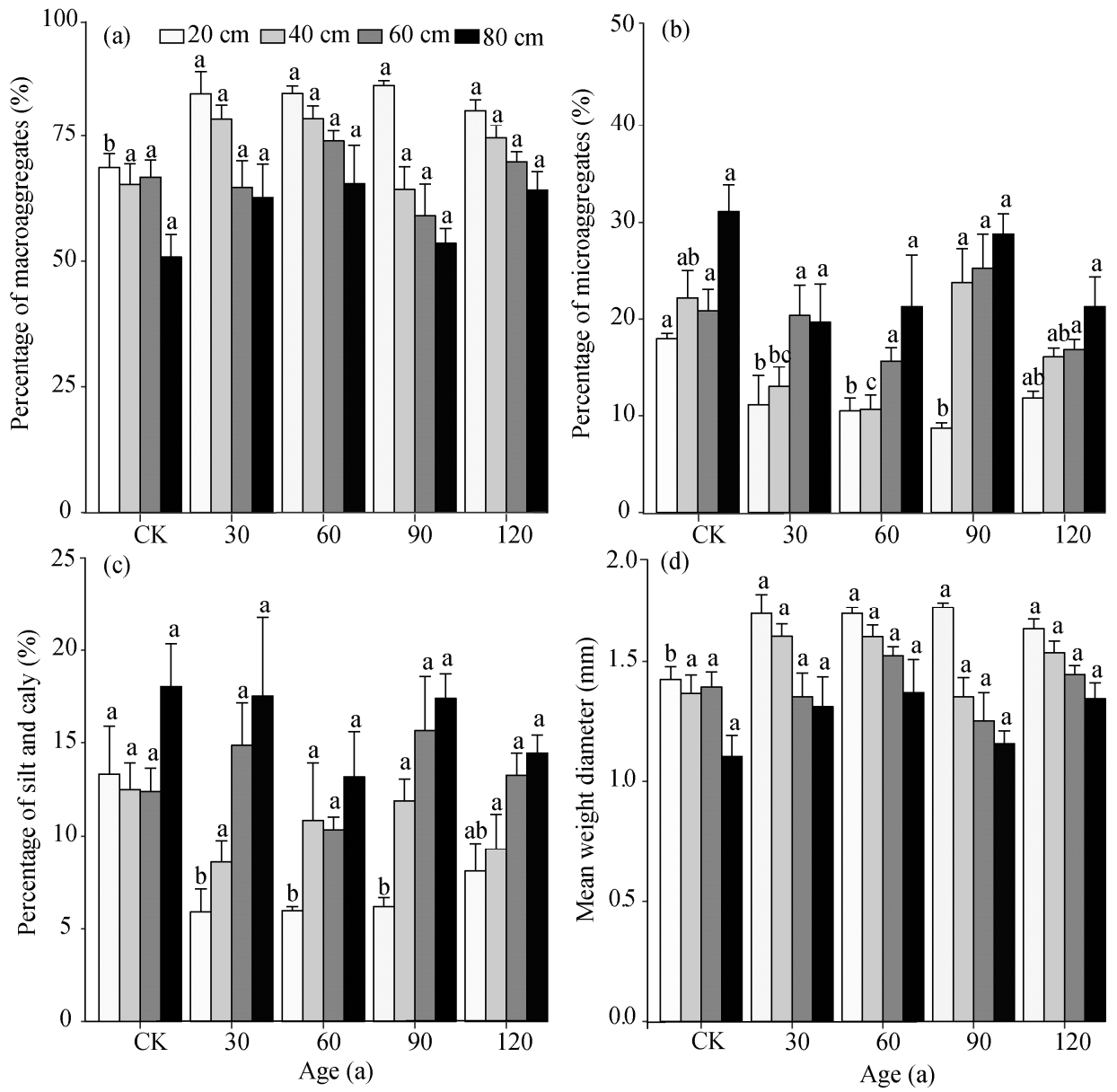

Fig. 1 Percentages of macroaggregates (a), microaggregates (b) and silt and clay (c) and mean weight diameter (d) of Liaodong oak forests in different restoration ages and soil layers. Different lowercase letters indicate significant differences among different restoration ages of the same soil layer at $P<0.05$ level. Bars mean standard errors.

\subsection{SOC contents and SOC components in different soil aggregate fractions}

Contents of SOC, HAC, AC and IC in aggregate fractions of topsoil increased with restoration ages and were higher in 60-year-old forest than those of control (Fig. 2). Moreover, they were $62.32 \%, 77.41 \%$ and $132.88 \%$ higher in the macroaggregates, $136.71 \%, 169.09 \%$ and $218.25 \%$ higher in the microaggregates, and $73.66 \%, 85.76 \%$ and $97.97 \%$ higher in the silt and clay, respectively than those of control. The content of IC increased most rapidly among all soil aggregate fractions.

\subsection{Proportion of SOC components in soil aggregate fractions}

Content of IC in the macroaggregates of topsoil was the greatest in the 90 -year-old forest, and the ratio of IC:AC:HAC was 5.74:1.87:1.00. Similarly, content of IC in the microaggregates was the greatest in the 90-year-old forest, and the ratio of IC:AC:HAC was 6.57:2.29:1.00. In contrast, content of IC in the silt and clay was the greatest in the 120-year-old forest, and the ratio of IC:AC:HAC was 4.29:1.84:1.00 (Table 2).

Contents of IC and AC in the macroaggregates of deep soil were the greatest in the 60-year-old forest, and the ratio of IC:AC:HAC was 3.58:3.96:1.00. Similarly, contents of IC and AC in the microaggregates and silt and clay fractions were the greatest in the 60-year-old forest, while the 
ratios of IC:AC:HAC in the microaggregates and silt and clay fractions were $3.35: 3.17: 1.00$ and 2.65:4.50:1.00, respectively (Table 2).
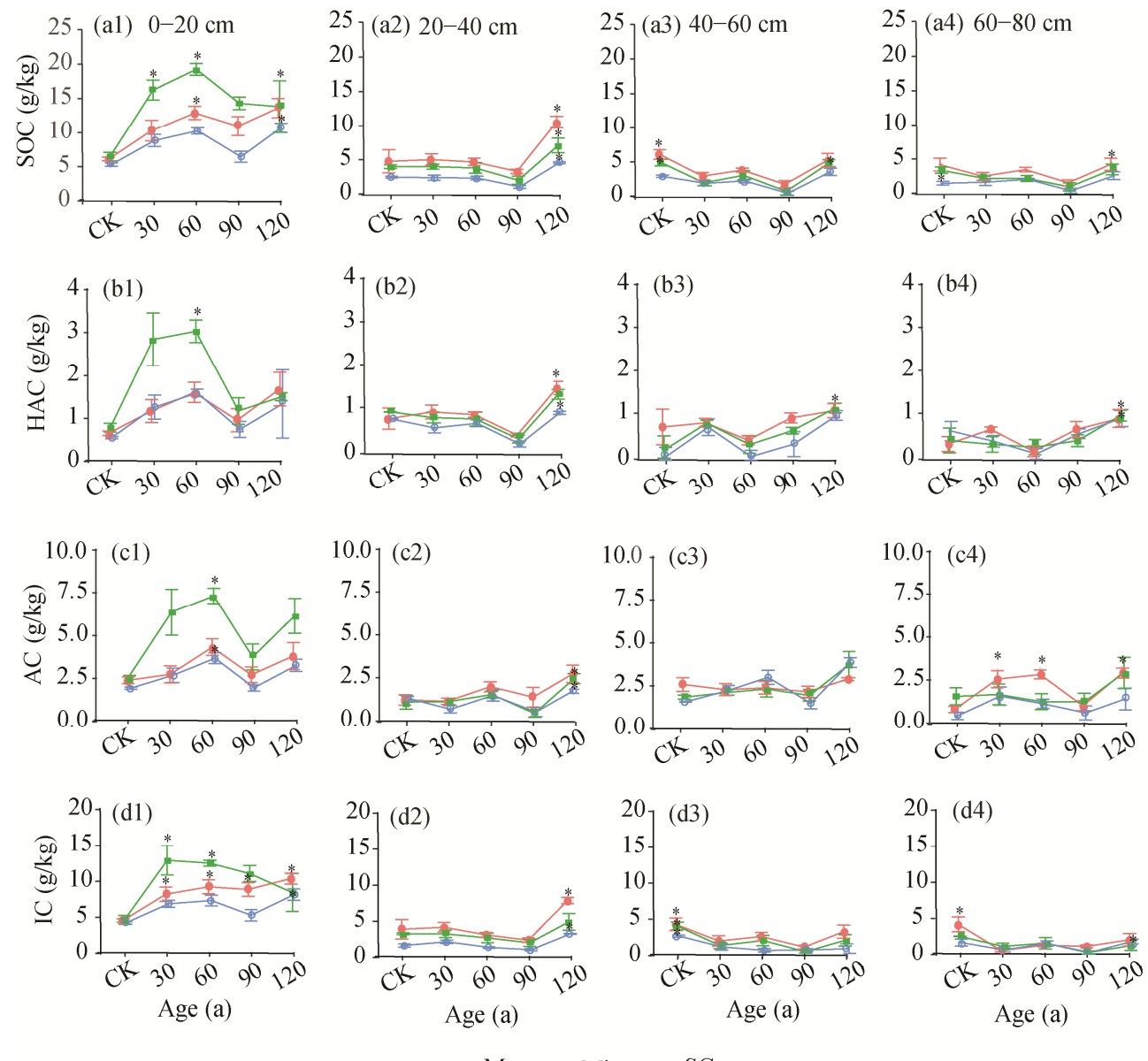

Fig. 2 Contents of SOC and SOC components of Liaodong oak forests in different restoration ages and soil layers. SOC, soil organic carbon; HAC, high activated carbon; AC, activated carbon; IC, inert carbon; Ma, macroaggregates; Mi, microaggregates; SC, silt and clay. ${ }^{*}$ indicates significant differences among different restoration ages of the same SOC components at $P<0.05$ level. Bars mean standard errors.

\subsection{Relationship between soil aggregate fractions and SOC components}

We found that IC and HAC contents in topsoil and deep soil were positively associated with the macroaggregates (Pearson's correlation coefficients were 0.52 and 0.42 , respectively), but there was little association with the microaggregates and silt and clay fractions (Fig. 3).

\subsection{Leaf and root biomasses}

We found that biomasses of thick roots and leaves followed similar trends, peaking in the 60 -year-old forest $\left(20.09 \mathrm{t} / \mathrm{hm}^{2}\right)$ and in the 90-year-old forest $\left(9.90 \mathrm{t} / \mathrm{hm}^{2}\right)$, respectively. Biomasses of finer and finest roots in topsoil progressively increased with forest restoration ages and reached 11.71 and $5.89 \mathrm{t} / \mathrm{hm}^{2}$ in the 120 -year-old forest, respectively, while biomass of finer roots in deep soil peaked in the 120-year-old forest (Tables 3 and 4).

\subsection{Relationship between SOC components and biomasses of roots and leaf litter in different soil aggregate fractions}

We found that the greatest and indirect impact on the content of the macroaggregates in topsoil was from finer root biomass (indirect path coefficient=1.70) and the greatest direct impact was 
from thick root and leaf litter biomasses (direct path coefficient=0.81) (Fig. 4). Sequestration of HAC in topsoil layer $(0-20 \mathrm{~cm})$ was the greatest in the macroaggregates (direct path coefficient=3.27). There was a positive correlation between the macroaggregates and IC content.

In deep soil layer $(20-80 \mathrm{~cm})$, finer root biomass had the greatest indirect impact on the content of the macroaggregates (indirect path coefficient $=0.17$ ), while thick root and leaf litter biomasses had the greatest impact (direct path coefficient=0.15). Sequestration of HAC was greatest in the macroaggregates (direct path coefficient $=0.35$ ), and there was a positive correlation between the macroaggregates and $\mathrm{AC}$ content.

Table 2 Effects of restoration age of Liaodong oak forests on proportion of SOC components in soil aggregate fractions

\begin{tabular}{|c|c|c|c|c|c|c|}
\hline \multirow{2}{*}{$\begin{array}{l}\text { Soil layer } \\
\quad(\mathrm{cm})\end{array}$} & \multirow{2}{*}{$\begin{array}{c}\text { SOC } \\
\text { component }\end{array}$} & \multicolumn{5}{|c|}{ Age (a) } \\
\hline & & $\mathrm{CK}$ & 30 & 60 & 90 & 120 \\
\hline \multirow[t]{6}{*}{$0-20$} & $\mathrm{MaAH}$ & $1.98 \pm 0.09^{\mathrm{a}}$ & $1.66 \pm 0.11^{\mathrm{a}}$ & $2.18 \pm 0.14^{\mathrm{a}}$ & $1.86 \pm 0.06^{\mathrm{a}}$ & $1.81 \pm 0.17^{\mathrm{a}}$ \\
\hline & MaIH & $2.05 \pm 0.12^{\mathrm{a}}$ & $2.09 \pm 0.13^{\mathrm{a}}$ & $2.31 \pm 0.07^{\mathrm{a}}$ & $2.38 \pm 0.57^{\mathrm{a}}$ & $3.25 \pm 0.59^{\mathrm{a}}$ \\
\hline & $\mathrm{MiAH}$ & $1.74 \pm 0.02^{\mathrm{a}}$ & $1.58 \pm 0.03^{\mathrm{a}}$ & $1.88 \pm 0.21^{\mathrm{a}}$ & $1.63 \pm 0.28^{\mathrm{a}}$ & $2.46 \pm 0.74^{\mathrm{a}}$ \\
\hline & MiIH & $3.10 \pm 0.23^{\mathrm{b}}$ & $4.71 \pm 0.37^{\mathrm{ab}}$ & $4.51 \pm 0.53^{\mathrm{ab}}$ & $5.85 \pm 0.44^{\mathrm{a}}$ & $5.23 \pm 0.85^{\mathrm{ab}}$ \\
\hline & SCAH & $2.87 \pm 0.29^{\mathrm{b}}$ & $4.34 \pm 0.33^{\mathrm{ab}}$ & $3.95 \pm 0.12^{\mathrm{ab}}$ & $6.78 \pm 1.11^{\mathrm{a}}$ & $4.24 \pm 1.52^{\mathrm{ab}}$ \\
\hline & $\mathrm{SCIH}$ & $2.99 \pm 0.12^{\mathrm{a}}$ & $3.78 \pm 0.34^{\mathrm{a}}$ & $3.39 \pm 0.29^{\mathrm{a}}$ & $3.77 \pm 0.85^{\mathrm{a}}$ & $5.88 \pm 1.49^{\mathrm{a}}$ \\
\hline \multirow[t]{6}{*}{$20-80$} & $\mathrm{MaAH}$ & $3.53 \pm 0.82^{\mathrm{ab}}$ & $2.54 \pm 0.30^{\mathrm{ab}}$ & $4.63 \pm 0.80^{\mathrm{a}}$ & $2.33 \pm 0.27^{\mathrm{b}}$ & $2.69 \pm 0.38^{\mathrm{ab}}$ \\
\hline & MaIH & $4.24 \pm 1.08^{\mathrm{a}}$ & $2.96 \pm 0.53^{\mathrm{a}}$ & $4.01 \pm 0.71^{\mathrm{a}}$ & $2.53 \pm 0.31^{\mathrm{a}}$ & $2.65 \pm 0.28^{\mathrm{a}}$ \\
\hline & $\mathrm{MiAH}$ & $3.40 \pm 0.97^{\mathrm{ab}}$ & $2.81 \pm 0.37^{\mathrm{ab}}$ & $5.76 \pm 1.14^{\mathrm{a}}$ & $3.05 \pm 0.75^{\mathrm{ab}}$ & $2.50 \pm 0.31^{\mathrm{b}}$ \\
\hline & MiIH & $5.36 \pm 1.04^{\mathrm{a}}$ & $2.25 \pm 0.45^{\mathrm{b}}$ & $4.23 \pm 0.70^{\mathrm{ab}}$ & $2.16 \pm 0.40^{\mathrm{b}}$ & $3.13 \pm 0.48^{\mathrm{ab}}$ \\
\hline & SCAH & $5.62 \pm 1.10^{\mathrm{a}}$ & $2.85 \pm 0.7^{\mathrm{ab}}$ & $3.68 \pm 0.94^{\mathrm{ab}}$ & $1.59 \pm 0.42^{\mathrm{b}}$ & $2.10 \pm 0.41^{\mathrm{ab}}$ \\
\hline & $\mathrm{SCIH}$ & $4.49 \pm 1.00^{\mathrm{a}}$ & $2.00 \pm 0.30^{\mathrm{a}}$ & $4.16 \pm 0.97^{\mathrm{a}}$ & $2.70 \pm 0.89^{\mathrm{a}}$ & $1.95 \pm 0.40^{\mathrm{a}}$ \\
\hline
\end{tabular}

Note: $\mathrm{MaAH}$, ratio of activated carbon to high activated carbon content in the macroaggregates; MaIH, ratio of inert carbon to high activated carbon content in the macroaggregates; MiAH, ratio of activated carbon to high activated carbon content in the microaggregates; MiIH, ratio of inert carbon to high activated carbon content in the microaggregates; SCAH, ratio of activated carbon to high activated carbon content in the silt and clay; $\mathrm{SCIH}$, ratio of inert carbon to high activated carbon content in the silt and clay. The abbreviations are the same in Figure 3. Mean \pm SD. Different lowercase letters within a row indicate significant among different restoration ages of the same SOC components at $P<0.05$ level.

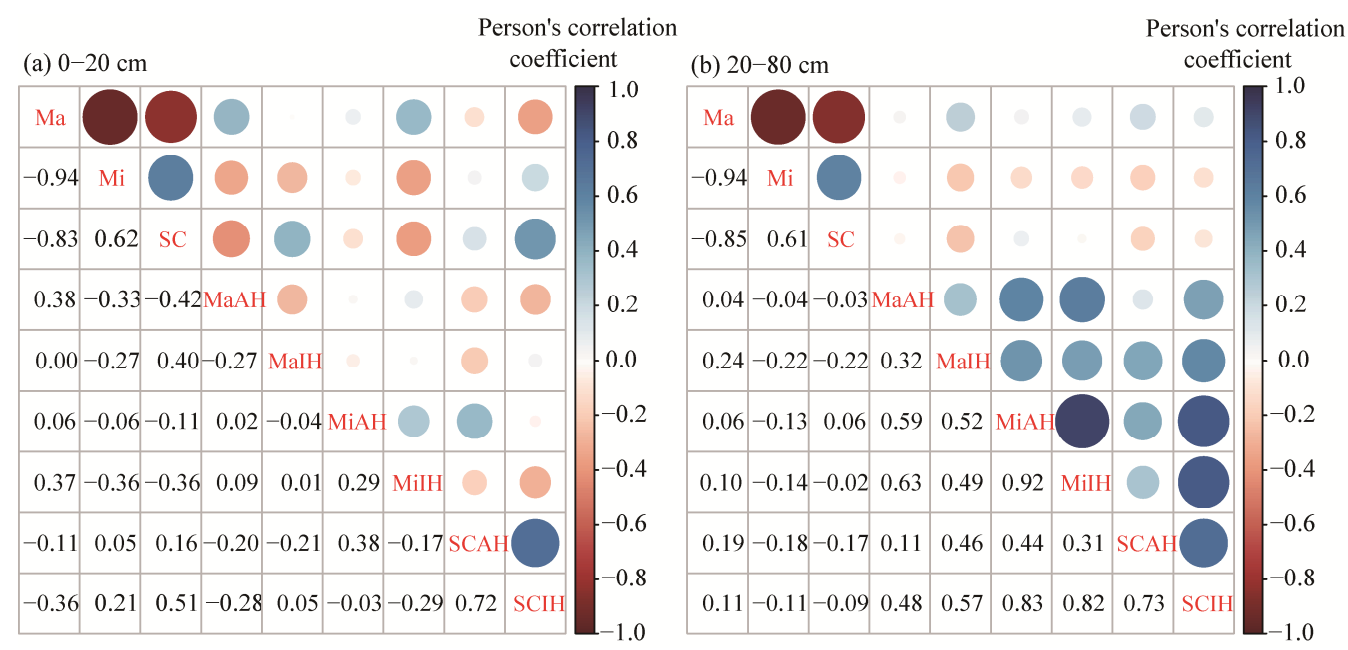

Fig. 3 Pearson's correlation coefficients of SOC components in soil aggregate fractions and different soil layers. (a), 0-20 cm; (b), 20-80 cm. Ma, macroaggregates; Mi, microaggregates; SC, silt and clay. 
Table 3 Biomasses of different sizes of roots in different soil layers and restoration ages

\begin{tabular}{|c|c|c|c|c|c|}
\hline \multirow{2}{*}{ Soil layer (cm) } & \multirow{2}{*}{ Age (a) } & \multicolumn{4}{|c|}{ Root biomass $\left(\mathrm{t} / \mathrm{hm}^{2}\right)$} \\
\hline & & $\mathrm{TR}(>2.0 \mathrm{~mm})$ & FR $(1.0-2.0 \mathrm{~mm})$ & FRer $(0.5-1.0 \mathrm{~mm})$ & FRest $(<0.5 \mathrm{~mm})$ \\
\hline \multirow[t]{5}{*}{$0-20$} & CK & $1.40 \pm 0.00^{\mathrm{b}}$ & $1.13 \pm 0.13^{\mathrm{c}}$ & $0.41 \pm 0.02^{\mathrm{b}}$ & $0.19 \pm 0.04^{\mathrm{c}}$ \\
\hline & 30 & $18.82 \pm 7.11^{\mathrm{a}}$ & $9.09 \pm 0.74^{\mathrm{ab}}$ & $7.38 \pm 0.91^{\mathrm{a}}$ & $3.21 \pm 0.28^{\mathrm{ab}}$ \\
\hline & 60 & $20.09 \pm 4.13^{\mathrm{a}}$ & $7.85 \pm 2.08^{\mathrm{b}}$ & $8.96 \pm 0.42^{\mathrm{a}}$ & $2.98 \pm 0.21^{\mathrm{b}}$ \\
\hline & 90 & $19.25 \pm 4.68^{\mathrm{a}}$ & $14.56 \pm 0.93^{\mathrm{a}}$ & $9.67 \pm 2.18^{\mathrm{a}}$ & $3.62 \pm 0.36^{\mathrm{ab}}$ \\
\hline & 120 & $18.82 \pm 6.16^{\mathrm{a}}$ & $8.67 \pm 1.37^{b}$ & $11.71 \pm 1.54^{\mathrm{a}}$ & $5.89 \pm 1.31^{\mathrm{ab}}$ \\
\hline \multirow[t]{5}{*}{$20-40$} & CK & $0.70 \pm 0.30^{\mathrm{b}}$ & $1.09 \pm 0.30^{\mathrm{b}}$ & $0.85 \pm 0.24^{\mathrm{b}}$ & $0.84 \pm 0.06^{\mathrm{a}}$ \\
\hline & 30 & $9.18 \pm 3.82^{\mathrm{b}}$ & $4.39 \pm 1.49^{\mathrm{a}}$ & $3.39 \pm 0.95^{\mathrm{ab}}$ & $1.00 \pm 0.34^{\mathrm{a}}$ \\
\hline & 60 & $27.99 \pm 9.16^{\mathrm{b}}$ & $6.67 \pm 2.14^{\mathrm{a}}$ & $4.26 \pm 0.40^{\mathrm{a}}$ & $0.97 \pm 0.23^{\mathrm{a}}$ \\
\hline & 90 & $47.48 \pm 6.32^{\mathrm{b}}$ & $5.98 \pm 1.27^{\mathrm{a}}$ & $3.07 \pm 0.77^{\mathrm{ab}}$ & $1.41 \pm 0.51^{\mathrm{a}}$ \\
\hline & 120 & $181.96 \pm 22.2^{\mathrm{a}}$ & $4.61 \pm 0.72^{\mathrm{a}}$ & $3.63 \pm 0.64^{\mathrm{ab}}$ & $1.19 \pm 0.07^{\mathrm{a}}$ \\
\hline \multirow[t]{5}{*}{$40-60$} & CK & $0.90 \pm 0.16^{\mathrm{b}}$ & $0.90 \pm 0.09^{\mathrm{b}}$ & $0.41 \pm 0.03^{\mathrm{b}}$ & $0.23 \pm 0.11^{\mathrm{b}}$ \\
\hline & 30 & $18.39 \pm 7.93^{\mathrm{ab}}$ & $3.38 \pm 0.51^{\mathrm{ab}}$ & $2.24 \pm 0.82^{\mathrm{a}}$ & $0.42 \pm 0.11^{\mathrm{ab}}$ \\
\hline & 60 & $17.53 \pm 8.28^{\mathrm{ab}}$ & $3.02 \pm 0.41^{\mathrm{ab}}$ & $1.81 \pm 0.26^{\mathrm{a}}$ & $0.53 \pm 0.17^{\mathrm{ab}}$ \\
\hline & 90 & $44.61 \pm 10.56^{\mathrm{a}}$ & $5.11 \pm 0.89^{\mathrm{a}}$ & $1.86 \pm 0.47^{\mathrm{a}}$ & $1.09 \pm 0.33^{\mathrm{a}}$ \\
\hline & 120 & $25.11 \pm 7.16^{\mathrm{ab}}$ & $3.14 \pm 0.76^{\mathrm{ab}}$ & $2.29 \pm 0.29^{\mathrm{a}}$ & $0.76 \pm 0.1^{\mathrm{ab}}$ \\
\hline \multirow[t]{5}{*}{$60-80$} & CK & $1.40 \pm 0.00^{\mathrm{b}}$ & $1.13 \pm 0.13^{\mathrm{c}}$ & $0.41 \pm 0.02^{b}$ & $0.19 \pm 0.04^{\mathrm{c}}$ \\
\hline & 30 & $18.82 \pm 7.11^{\mathrm{a}}$ & $9.09 \pm 0.74^{\mathrm{ab}}$ & $7.38 \pm 0.91^{\mathrm{a}}$ & $3.21 \pm 0.28^{\mathrm{ac}}$ \\
\hline & 60 & $20.09 \pm 4.13^{\mathrm{a}}$ & $7.85 \pm 2.08^{\mathrm{b}}$ & $8.96 \pm 0.42^{\mathrm{a}}$ & $2.98 \pm 0.21^{\mathrm{b}}$ \\
\hline & 90 & $19.25 \pm 4.68^{\mathrm{a}}$ & $14.56 \pm 0.93^{\mathrm{a}}$ & $9.67 \pm 2.18^{\mathrm{a}}$ & $3.62 \pm 0.36^{\mathrm{ac}}$ \\
\hline & 120 & $18.82 \pm 6.16^{\mathrm{a}}$ & $8.67 \pm 1.68^{\mathrm{b}}$ & $11.71 \pm 1.54^{\mathrm{a}}$ & $5.89 \pm 1.31^{\mathrm{a}}$ \\
\hline
\end{tabular}

Note: TR, thick root; FR, fine root; FRer, finer root; FRest, finest root. Different lowercase letters within a column indicate significant differences among different forest restoration ages of the same soil layer at $P<0.05$ level.

Table 4 Litter biomass in different restoration ages

\begin{tabular}{cc}
\hline Age (a) & Litter biomass $\left(\mathrm{t} / \mathrm{hm}^{2}\right)$ \\
\hline CK & $3.26 \pm 0.19^{\mathrm{b}}$ \\
30 & $7.67 \pm 0.75^{\mathrm{a}}$ \\
60 & $8.93 \pm 0.31^{\mathrm{a}}$ \\
90 & $9.90 \pm 0.79^{\mathrm{a}}$ \\
120 & $8.77 \pm 0.67^{\mathrm{a}}$ \\
\hline
\end{tabular}

Note: Different lowercase letters within a column indicate significant differences among different restored forest ages at $P<0.05$ level.

\section{Discussion}

\subsection{Effects of restoration ages on soil aggregate fractions and SOC components}

We found that content of SOC components among the aggregate fractions of topsoil increased with ages of forest restoration, in which IC in the macroaggregates increased most rapidly, and the ratio of IC to HAC limited the content of water-stable aggregate fractions, which supporting our hypothesis to some extent.

We found an increase in the content of the macroaggregates with vegetation restoration, while that of the microaggregates and silt and clay fractions decreased. These results are consistent with a previous study (An et al., 2013). Restoration is beneficial for the formation of aggregate fractions by providing suitable physical, chemical and microbiological conditions in the rhizosphere (root, root secretions and litter) for creation of soil particles (Zhang et al., 2016). In addition, the development of plant rhizosphere microorganisms produces greater abundance of mycelia (Zhang et al., 2016). We found that finer root $(0.5-1.0 \mathrm{~mm})$ biomass had the greatest 

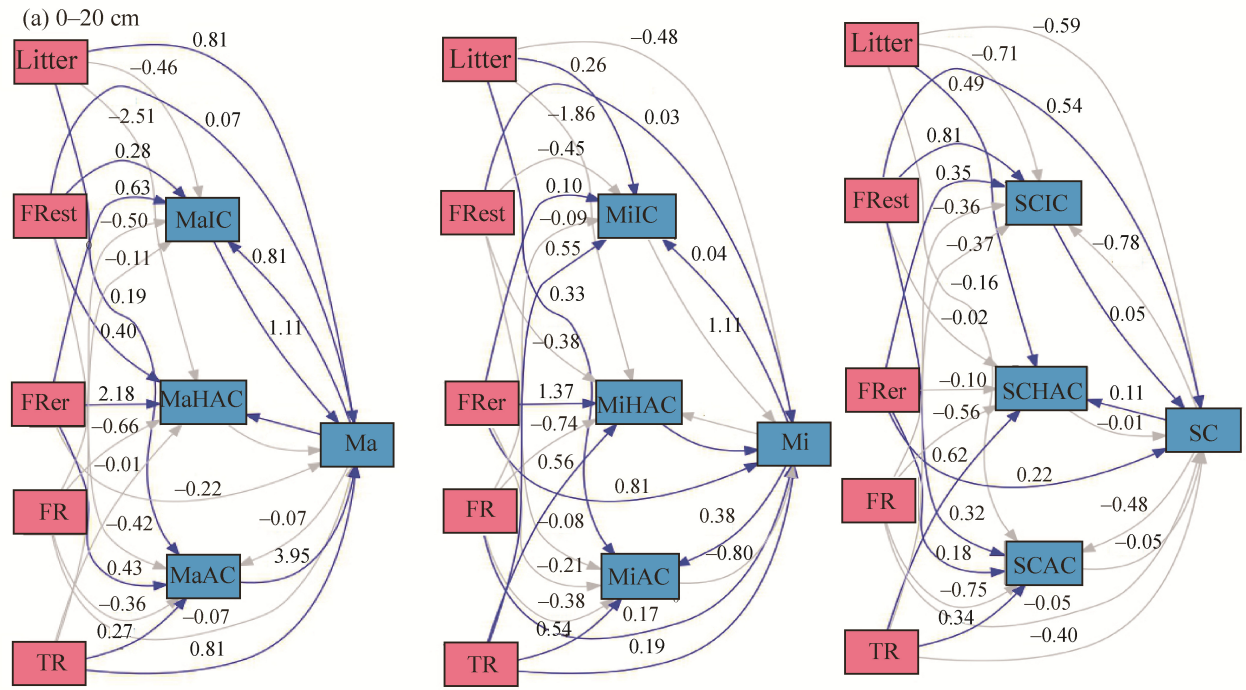

(b) $20-80 \mathrm{~cm}$
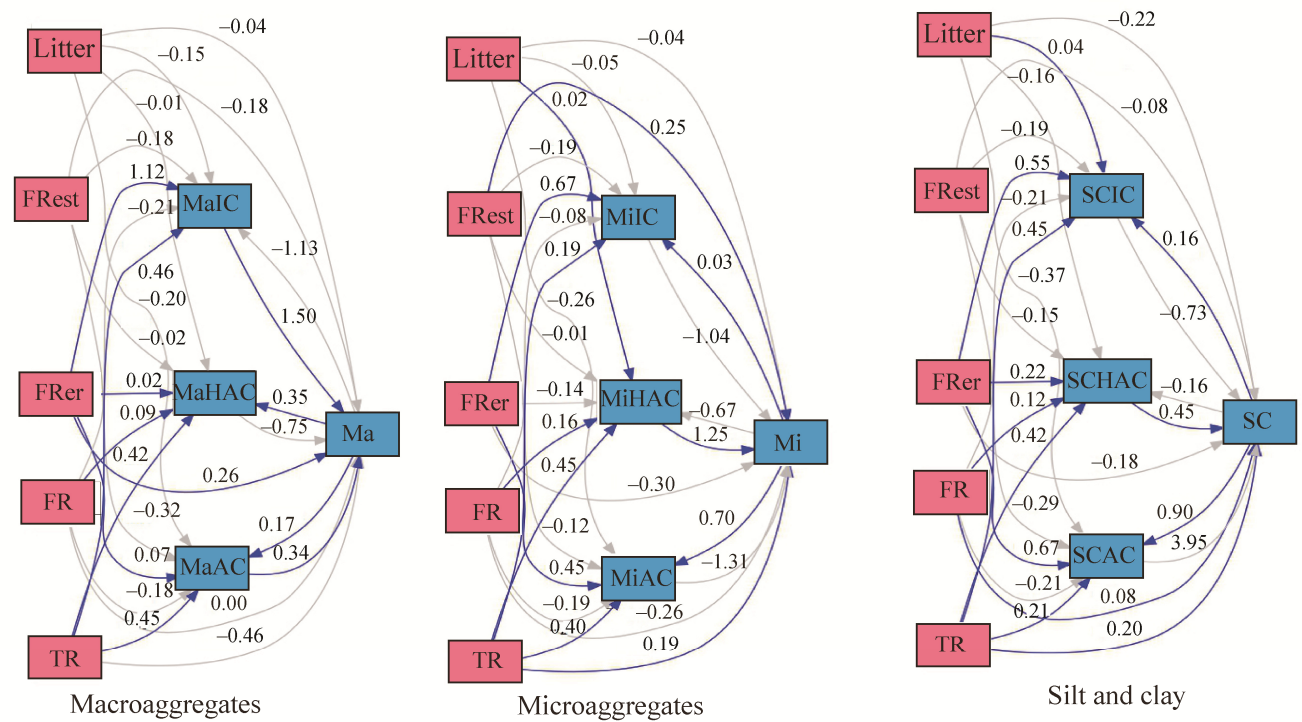

Fig. 4 Relationship between SOC components and biomasses of different size of roots and leaf litter in soil aggregate fractions and different soil layers. (a), 0-20 cm; (b), 20-80 cm. Litter, leaf litter; FRest, finest root; FRer, finer root; FR, fine root; TR, thick root; SCIC, inert carbon content in the silt and clay; SCHAC, high activated carbon content in silt and clay; SCAC, activated carbon content in the silt and clay; SC, silt and clay. Grey line indicates negative coefficient, while blue line indicates positive coefficient.

impact on the aggregate fractions in topsoil, whereas thick root $(>2.0 \mathrm{~mm})$ biomass had the greatest impact on the aggregate fractions in deep soil. We suggest that the microaggregates, silt and clay and macroaggregates fractions were affected by the same sources of carbon source during vegetation restoration in revegetated forests.

Total contents of SOC, HAC, AC and IC in all topsoil aggregate fractions generally increased with restoration ages, supporting the results from previous research (Cheng et al., 2015). We comprehensively analyzed the content of SOC components among aggregate fractions, and found the strongest relationship between macroaggregate content and the ratio of IC to HAC. Natural vegetation restoration changes the ratio of SOC components in soil aggregate fractions (Zhang et al., 2016), in which SOC in the structure of clay mineral laminates is encompassed by organic binding material within the aggregate fractions (Tisdall, 1994). We analyzed HAC, AC and IC, 
and found that they changed overall structure of aggregate fractions, probably as a result of their physical and chemical properties that affected molecular forces, chemical bonds and cohesive forces. Annual increases in plant leaf and root litter biomasses continuously provided the sources of carbon, thus, SOC content increased with restoration ages. We also found that contents of HAC, $\mathrm{AC}$ and IC changed; however, IC content was positively associated with a rise in aggregate fractions. Thus, natural vegetation restoration can be considered as a driver of soil development, and carbon sequestration and carbon release from soil aggregate fractions continuously changed the ratios of SOC components. Other studies confirmed that $\mathrm{AC}$ content in the macroaggregates is greater than that in the microaggregates (Spaccini et al., 2001), because organic matter in the macroaggregates was more readily decomposed, while that in the microaggregates was more stable. Contents of HAC and IC in the macroaggregates in this study was higher than those in the other fractions of aggregates, so we concluded that IC was the main source of carbon sequestration in the macroaggregates. The addition of fresh biochar to soil rapidly converts to stable soil carbon (Kelly et al., 2017), and forest succession increases carbon storage, especially the ratio of stable organic carbon (Xiang et al., 2015). Chemical properties of IC are stable, and are allied to soil humus that is the primary source $(50 \%-65 \%)$ of soil organic matter. The primary types of IC are humic and fulvic acids with a moderate bonding ability, and are capable of bonding silt and clay to form a granular structure (Wu et al., 2011). Organic matter that contains humic and fulvic acids, and inorganic substances, such as amorphous iron, aluminum oxide, calcium carbonate, magnesium and aluminum silicate, were incorporated to form an organic and inorganic complex that constitutes the aggregate core (Tisdall et al., 1982). However, the contents of the macroaggregates and MWD did not increase with increasing IC ratio. This finding indicates that the macroaggregates collapsed, microaggregates and organic matter were released at some point (Six et al., 1999). We found the content of the macroaggregates decreased when the ratio of IC to HAC exceeded 5.74, and as plant residues in the soil rapidly increased, the contents of aggregate and MWD similarly increased. It is likely that the source of fresh carbon in the macroaggregates was transformed into stable IC as a result of microorganism activity, and the IC was primarily incorporated by inorganic substances with chemical bonds (calcium, iron and aluminum). Moreover, the increase in IC content may have been a result of weak molecular forces that prevent the formation of macromolecular compounds. Here, we implied that the increase in IC content restricted the further formation of the macroaggregates, since there were lower contents of the macroaggregates and MWD.

\subsection{Effects of biomasses of roots and leaf litter on aggregate fractions and SOC components}

Sequestration of HAC was the greatest in topsoil and the contents of the macroaggregatess and macroaggregates in topsoil was mostly affected by litter and finer root $(0.5-1.0 \mathrm{~mm})$ biomasses. Furthermore, there was an association between the macroaggregates and IC content. Impacts of finer root biomass on the contents of the microaggregates were greater than those of the other sizes of roots. We also found that roots entered the soil and subsequently generated root litter and secretions as a result of continuous metabolism of root system that forms rhizosphere aggregate around the root system during restoration. Theoretically, MWD increased with root diameter, therefore, it is likely that the micro-ecosystem structure of the macroaggregates was stronger, and was composed of plant roots, soil microbes and fauna, metabolic secretions and soil particles (Cambardella et al., 1994). Turnover volume of thick root ( $>2 \mathrm{~mm}$ ) biomass was greater than that of the other sizes of roots, which potentially produced the greatest amount of biomass in topsoil (Yuan et al., 2010). Thus, thick roots were major source of SOC components in the macroaggregates that could encapsulate, decompose and fix larger size of root.

Effects of thick root biomass on the content of the macroaggregates in deep soil were greater than those of other sizes of roots, in which sequestration of HAC was the greatest. There was a positive correlation between the contents of the macroaggregates and $\mathrm{AC}$, and thick root biomass had the greatest impact on the microaggregates and silt and clay fractions. Unlike in topsoil, there were a greater proportion of thick roots, and these larger roots provide better support for plant 
growth (Freschet et al., 2017). It is also likely that these thick roots could increase access to moisture in deep soil during dry season to maintain a normal metabolism.

\subsection{Effects of restoration ages on proportion of SOC components in soil aggregate fractions}

The changes in proportions of SOC components in deep soil lagged behind those in surface soil in restored forests, which is consistent with the results from previous studies (Alcantara et al., 2017). Finer root biomass and leaf litter had the greatest impacts on the proportion of topsoil aggregate fractions, whereas thick root biomass had the greatest impact on the proportions of deep soil aggregate fractions. These results indicated that aggregate formation in topsoil and deep soil were mainly influenced by the differences in root sizes. The content of the macroaggregates peaked at the 90-year-old forest in topsoil and at the 120-year-old forest in deep soil, while SOC content peaked at the 60-year-old forest in topsoil and at the 120-year-old forest in deep soil. In topsoil, SOC was rich due to leaf and root litter, whereas SOC was limited in deep soil due to the relatively less root litter and lower rates of decomposition of organic matter.

\section{Conclusions}

This study showed that natural vegetation restoration of Liaodong oak forests increased the contents of the macroaggregates and SOC in topsoil and deep soil, especially the IC. Moreover, IC had the greatest effect on the stability of aggregate fractions. Biomasses of roots $(0.5-1.0 \mathrm{~mm})$ and leaf litter in topsoil affected IC, while roots $>2.0 \mathrm{~mm}$ in deep soil affected IC. Our study demonstrated that restoration of natural forests improved carbon sequestration capacity in the macroaggregates.

\section{Acknowledgements}

This research was funded by the National Key Research and Development Program of China (2017YFC0504601), the Science and Technology Service Network Initiative of Chinese Academy of Sciences (KFJ-STS-ZDTP-036) and the National Natural Science Foundation of China (41671513).

\section{References}

Alcantara V, Don A, Vesterdal L, et al. 2017. Stability of buried carbon in deep-ploughed forest and cropland soils-implications for carbon stocks. Scientific Reports, 7(1): 5511.

An S, Darboux F, Cheng M. 2013. Revegetation as an efficient means of increasing soil aggregate stability on the Loess Plateau (China). Geoderma, 209: 75-85.

Barthes B G, Kouakoua E, Larre-Larrouy M, et al. 2008. Texture and sesquioxide effects on water-stable aggregates and organic matter in some tropical soils. Geoderma, 143(1-2): 14-25.

Bi X, Li B, Nan B, et al. 2018. Characteristics of soil organic carbon and total nitrogen under various grassland types along a transect in a mountain-basin system in Xinjiang, China. Journal of Arid Land, 10(4): 612-627.

Callesen I, Harrison R, Stupak I, et al. 2016. Carbon storage and nutrient mobilization from soil minerals by deep roots and rhizospheres. Forest Ecology and Management, 359: 322-331.

Cambardella C A, Elliott E T. 1993. Carbon and nitrogen distribution in aggregates from cultivated and native grassland soils. Soil Science Society of America Journal, 57(4): 1071-1076.

Chan K Y, Bowman A, Oates A. 2001. Oxidizable organic carbon fractions and soil quality changes in an Oxic paleustalf under different pasture leys. Soil Science, 166(1): 61-67.

Cheng M, Xiang Y, Xue Z, et al. 2015. Soil aggregation and intra-aggregate carbon fractions in relation to vegetation succession on the Loess Plateau, China. Catena, 124: 77-84.

Elliott E T. 1986. Aggregate structure and carbon, nitrogen, and phosphorus in native and cultivated soils. Soil Science Society of America Journal, 50(3): 627-633.

Freschet G T, Roumet C. 2017. Sampling roots to capture plant and soil functions. Functional Ecology, 31(8): 1506-1518.

He N, Wen D, Zhu J, et al. 2017. Vegetation carbon sequestration in Chinese forests from 2010 to 2050. Global Change Biology, 23(4): 1575-1584.

Kelly C N, Benjamin J, Calderon F C, et al. 2017. Incorporation of biochar carbon into stable soil aggregates: the role of clay 
mineralogy and other soil characteristics. Pedosphere, 27(4): 694-704.

Li L Q, Wang D, Liu X Y, et al. 2014. Soil organic carbon fractions and microbial community and functions under changes in vegetation: a case of vegetation succession in karst forest. Environmental Earth Sciences, 71(8): 3727-3735.

Liao H K, Long J, Li J. 2016. Conversion of cropland to Chinese prickly ash orchard affects soil organic carbon dynamics in a karst region of southwest China. Nutrient Cycling in Agroecosystems, 104(1): 15-23.

Lin G G, Zeng D H. 2017. Heterogeneity in decomposition rates and annual litter inputs within fine-root architecture of tree species: Implications for forest soil carbon accumulation. Forest Ecology and Management, 389: 386-394.

Sanaullah M, Chabbi A, Leifeld J, et al. 2011. Decomposition and stabilization of root litter in top- and subsoil horizons: what is the different? Plant and Soil, 338(1-2): 127-141.

Six J, Elliott E T, Paustian K. 1999. Aggregate and soil organic matter dynamics under conventional and no-tillage systems. Soil Science Society of America Journal, 63(5): 1350-1358.

Spaccini R, Zena A, Igwe C A, et al. 2001. Carbohydrates in water-stable aggregates and particle size fractions of forested and cultivated soils in two contrasting tropical ecosystems. Biogeochemistry, 53(1): 1-22.

Tisdall J M. 1994. Possible role of soil microorganisms in aggregation in soils. Plant and Soil, 159(1): 115-121.

Wang F M, Zhu W X, Chen H. 2016. Changes of soil C stocks and stability after 70-year afforestation in the Northeast USA. Plant and Soil, 401(1-2): 319-329.

Wang G L, Xue S, Liu F, et al. 2007. Nitrogen addition increases the production and turnover of the lower-order roots but not of the higher-order roots of Bothriochloa ischaemum. Plant and Soil, 415(1-2): 423-434.

Wei X R, Li X Z, Jia X X, et al. 2013. Accumulation of soil organic carbon in aggregates after afforestation on abandoned farmland. Biology and Fertility of Soils, 49(6): 637-646.

Wu G L, Liu Y, Yang Z, et al. 2017. Root channels to indicate the increase in soil matrix water infiltration capacity of arid reclaimed mine soils. Journal of Hydrology, 546: 133-139.

Xiang H L, Zhang L L, Wen D Z. 2015. Change of soil carbon fractions and water-stable aggregates in a forest ecosystem succession in south china. Forests, 6(8): 2703-2718.

Yao X, Jing H, Liang C T. 2017. Response of labile organic carbon content in surface soil aggregates to short-term nitrogen addition in artificial Pinus tabulaeformis forests. Acta Ecologica Sinica, 37(20): 1-8. (in Chinese)

Yuan Z Y, Chen H Y. 2010. Fine root biomass, production, turnover rates, and nutrient contents in boreal forest ecosystems in relation to species, climate, fertility, and stand age: literature review and meta-analyses. Critical Reviews in Plant Sciences, 29(4): 204-221.

Zelenev V V, van Bruggen A, Semenov A M. 2000. "BACWAVE," a spatial-temporal model for traveling waves of bacterial populations in response to a moving carbon source in soil. Microbial Ecology, 40(3): 260-272.

Zhang H Q, Liu Z K, Chen H, et al. 2016. Symbiosis of arbuscular mycorrhizal fungi and Pobinia pseudoacacia L. improves root tensile strength and soil aggregate stability. PloS ONE, 11(4): e01533784.

Zhang X, Han S J, Wang S Q, et al. 2016. Change of soil organic carbon fractions at different successional stages of Betula platyphylla forest in Changbai Mountains. Chinese Journal of Ecology, 35(2): 282-289.

Zhou H, Peng X, Peth S, et al. 2012. Effects of vegetation restoration on soil aggregate microstructure quantified with synchrotron-based micro-computed tomography. Soil and Tillage Research, 124: 17-23.

Zhu B B, Li P, Li Z B, et al. 2008. Dynamics of water stable aggregate in land degradation/ restoration process of Ziwuling forest farm. Journal of Northwest Sci-Tech University of Agriculture and Forestry: Natural Science Edition, 36(3): 124-128. (in Chinese) 